\section{Effect of alendronate on endochondral ossification in mandibular condyles of growing rats}

\author{
V. Bradaschia-Correa, ${ }^{1}$ F.A.C. Barrence, ${ }^{2}$ \\ L.B. Ferreira, ${ }^{1}$ L.F. Massa, ${ }^{1}$ \\ V.E. Arana-Chavez ${ }^{1}$ \\ 'Division of Oral Biology, School of \\ Dentistry, University of São Paulo; \\ 2Department of Cell and Developmental \\ Biology, Institute of Biomedical Sciences, \\ University of São Paulo, Brazil.
}

\section{Abstract}

The replacement of the calcified cartilage by bone tissue during the endochondral ossification of the mandibular condyle is dependent of the resorbing activity of osteoclats. After partial resorption, calcified cartilage septa are covered by a primary bone matrix secreted by osteoblasts. Osteoadherin (OSAD) is a small proteoglycan present in bone matrix but absent in cartilage during the endochondral ossification. The aim of this study was to analyze the effect of alendronate, a drug known to inhibit bone resorption by osteoclasts, on the endochondral ossification of the mandibular condyle of young rats, by evaluating the distribution of osteoclasts and the presence of OSAD in the bone matrix deposited. Wistar newborn rats $(\mathrm{n}=45)$ received daily injections of alendronate $(\mathrm{n}=27)$ or sterile saline solution as control $(n=18)$ from the day of birth until the ages of 4,14 and 30 days. At the days mentioned, the mandibular condyles were collected and processed for transmission electron microscopy analysis. Specimens were also submitted to tartrate resistant acid phosphatase (TRAP) histochemistry and ultrastructural immunodetection of OSAD. Alendronate treatment did not impede the recruitment and fusion of osteoclasts at the ossification zone during condyle growth, but they presented inactivated phenotype. The trabeculae at the ossification area consisted of cartilage matrix covered by a layer of primary bone matrix that was immunopositive to OSAD at all time points studied. Apparently, alendronate impeded the removal of calcified cartilage and maturation of bone trabeculae in the mandibular ramus, while in controls they occurred normally. These findings highlight for giving attention to the potential side-effects of bisphosphonates administered to young patients once it may represent a risk of disturbing maxillofacial development.

\section{Introduction}

The mandibular condyle that develops by endochondral ossification is a growth site of the mandible. The temporomandibular joint is the only synovial joint in the body in which its bone surfaces are covered by a layer of dense connective tissue rather than by a hyaline (articular) cartilage, ${ }^{1}$ the same connective tissue that constitutes the temporomandibular articular disc. ${ }^{2}$ Early in embryonic development, however, endochondral ossification starts into a hyaline cartilage that arises from a condylar blastema. Therefore, as in other parts of the body where that process takes place, chondrocytes proliferate, become hypertrophied and then undergo apoptosis, providing a condition in which the cartilaginous matrix mineralizes. ${ }^{3}$ Clastic cells resorb some areas of calcified matrix for allowing capillaries and undifferentiated cells to invade the cavities previously filled by chondrocytes. ${ }^{4,5}$ The primary bone secreted over the calcified cartilage septa contains abundant collagen fibrils arranged in a disorganized network with interspersed noncollagenous proteins and proteoglycans. Differently from other small leucine-rich proteoglycans (SLRPs) present in the other connective tissues of the temporomandibular joint, ${ }^{6,7}$ osteoadherin (OSAD) is present in the extracellular matrix of bone and other mineralized tissues. ${ }^{8}$ In bone matrix, OSAD is localized into cement lines and mineralizing fronts, being absent into the mineralized cartilage that remain at the center of the bone trabeculae. ${ }^{9}$ Indeed, OSAD has been detected during endochondral ossification of rat femora, ${ }^{10}$ but its precise distribution has not been well established. The first layers of primary bone deposited over calcified cartilage are subsequently remodeled into mature bone. Thus, the association between resorptive activity by clastic cells and bone matrix formation by osteoblasts is crucial for the mandibular condyle growth.

Bisphosphonates are a class of drugs that inhibit osteoclast-mediated bone resorption, and are widely used in prevention and treatment of bone diseases such as osteoporosis, Paget's disease and metastatic bone cancer. ${ }^{11}$ Nitrogen-containing bisphosphonates cause disorders in clastic cell cytoskeleton and intracellular signaling, inhibit adhesion mechanisms and yield structural changes in the ruffle border, as well as decrease of their acid production. As a result, osteoclasts may become latent or inactive and subsequently undergo apoptosis $^{12,13}$ or only lose their resorptive ability, ${ }^{14}$ yielding to reduced bone remodeling ${ }^{15,16}$ and osteogenic potential. ${ }^{17}$

Sodium alendronate is widely employed in therapy of several pediatric and juvenile bone
Correspondence: Prof. Victor E. Arana-Chavez, Av. Prof. Lineu Prestes 2227, CEP 05508-900, São Paulo, Brazil. Tel/Fax: +55.11 .3091 .7840 .

E-mail: vearana@usp.br

Key words: endochondral ossification, osteoclast, chondroclast, alendronate, calcified cartilage, osteoadherin, condyle.

Acknowledgements: the authors would like to thank Dr. Françoise Bleicher (Université de Lyon, France) for supplying the anti-OSAD antibody and Mr. Gaspar Lima for ultrathin sectioning.

This work was supported by grants from FAPESP (06/60094-5 and 09/54853-9) and CNPq (Brazil).

Contributions: VBC, LFM, VEAC, study conception and design; VBC, FACB, LBF, LFM, treatment of rats and tissue preparation; FACB, TRAP histochemistry performing; VBC, ultrastructural immunocytochemistry performing; VBC, VEAC, article drafting and final manuscript writing.

Conflict of interests: the authors report no commercial, proprietary, or financial interest in the products or companies described in this article.

Received for publication: 24 January 2012.

Accepted for publication: 13 March 2012.

This work is licensed under a Creative Commons Attribution NonCommercial 3.0 License (CC BYNC 3.0).

(C) Copyright V. Bradaschia-Correa et al., 2012 Licensee PAGEPress, Italy

European Journal of Histochemistry 2012; 56:e24 doi:10.4081/ejh.2012.e24

disorders, ${ }^{18-20}$ and its administration can possibly induce alterations during skeletal growth of children. Several experiments have been carried out in the last decades in order to investigate the effects of bisphosphonates on skeletal and dental development. The administration of alendronate to young growing rats undergoing tooth development alters both enamel and dentin matrix; ${ }^{21}$ pamidronate treatment delays the eruption of rat teeth, ${ }^{22}$ while alendronate completely impairs the eruption of molars in rats. ${ }^{23}$ Alendronate reduces bone resorption and inhibits long bone growth in an osteogenesis imperfecta mouse model. ${ }^{24}$ Previous studies have reported the enlargement of the cartilage zone as effect of bisphosphonate treatment. ${ }^{25-29}$

The aim of this study was to investigate the effect of sodium alendronate on the endochondral ossification of the mandibular condyle of young rats. In order to test the hypothesis that this drug may affect the clastic activity during the endochondral ossification in the mandibular condyle, we treated newborn rats with sodium alendronate up to 30 days. Then, ultrastructural techniques were applied in order to 
examine whether clastic cells are present and their morphology, as well as the structure of the primary bone trabeculae. As OSAD is present at the primary bone but not into the calcified cartilage septa, high resolution immunocytochemical labeling was made for clearly distinguishing primary bone from cartilage.

\section{Materials and Methods}

\section{Animals}

Principles of laboratory animal care (NIH publication 85-23, 1985) and national laws on animal use were observed for the present study, which was authorized by the Ethical Committee for Animal Research of the University of São Paulo, Brazil. Forty-five newborn Wistar albino rats were used in this study. Twenty seven rats were subjected to daily subcutaneous injections of $2.5 \mathrm{mg} / \mathrm{kg}$ of sodium alendronate ${ }^{21,23}$ since the day of birth to 4,14 and 30 days old. Additional eighteen rats were daily injected with saline during the same periods. All the alendronate-treated rats were not weaned during the entire study in order to have their nutrition provided maternally.

\section{Tissue preparations}

At the time points cited, nine alendronatetreated and six control rats were anesthetized with $1 \mathrm{~mL} / \mathrm{kg}$ body weight of $2 \%$ chloridrate 2 (6,6-xilidine)-5,6-dihydro-4-H-1,3-tiazine diluted 1:1 in ketamine, decapitated and had their mandibular condyles dissected out and immediately fixed in $2 \%$ glutaraldehyde and $2.5 \%$ formaldehyde buffered in $0.1 \mathrm{M}$ sodium cacodylate, $\mathrm{pH}$ 7.4. Specimens were immersed in fixative solution at room temperature, which was placed in a Pelco 3440 laboratory microwave oven (Ted Pella, Redding, CA, USA) and then exposed to microwave irradiation at $100 \%$ setting for 3 cycles of $5 \mathrm{~min}$, with the temperature programmed to a maximum of $37^{\circ} \mathrm{C}$. After microwave irradiation, specimens were transferred into fresh fixative solution and left submersed in that overnight at $4^{\circ} \mathrm{C} .{ }^{30}$ They were rinsed in $0.05 \mathrm{M}$ cacodylate buffer and decalcified in $4.13 \%$ ethylenediaminetetraacetic acid (EDTA) for 20 days. Then, specimens were processed for embedding in different materials.

\section{Light microscopy}

The condylar processes from three alendronate-treated and two control rats from each group were dehydrated in graded ethanol concentrations and embedded in JB-4 historesin (Polysciences, Warrington, PA, USA). Three$\mu \mathrm{m}$ thick sections were collected onto glass slides stained in hematoxylin and acid fuchsin for morphological analysis, and additional sections were submitted to tartrate resistant acid phosphatase (TRAP) histochemistry. The sections were incubated in Burstone's complete medium (Sigma Chemical Co., St. Louis, M0, USA), which was prepared by dissolving $4 \mathrm{mg}$ naphtol As-Bi phosphate substrate in $0.25 \mathrm{~mL}$ of N-N-dimethylformamide, followed by addition of $25 \mathrm{~mL}$ of $0.2 \mathrm{M}$ acetate buffer $\mathrm{pH} 5.0,35$ mg of Fast Red Violet LB as the coupling agent and $60 \mu \mathrm{L}$ of $10 \% \mathrm{MgCl}$. Next, $25 \mathrm{~mL}$ of the medium was filtered into a Coplin jar and warmed to $37^{\circ} \mathrm{C}$, followed by the addition of 50 $\mathrm{mM} \mathrm{D}(-)$ tartaric acid. The slides containing the sections were incubated during $2 \mathrm{~h}$. After that, the slides were washed in tap water and counterstained with Harris' hematoxylin for 10 min. ${ }^{31}$ Coverslips were mounted with Entellan (Merck, Germany) and the slides were examined and photographed in an Olympus BX-60 light microscope.

\section{Transmission electron microscopy}

The condylar processes from other three alendronate-treated and two control rats from each time point were post-fixed in $0.1 \mathrm{M}$ cacodylate-buffered $1 \%$ osmium tetroxide for 2 $\mathrm{h}$ at room temperature, dehydrated in graded concentrations of alcohol, and embedded in Spurr resin (Electron Microscopy Sciences, PA, USA) for ultrastructural analyzes. Toluidine blue-stained $1 \mu \mathrm{m}$ thick sections were examined and endochondral ossification regions of the condyle were selected for ultrathin sectioning. Sections 80 -nm thick were obtained with a diamond knife on a Leica Ultracut R ultramicrotome (Leica, Buffalo, NY, USA), collected onto 200-mesh copper grids, stained with uranyl acetate and lead citrate, and examined in a Jeol 1010 transmission electron microscope operated at $80 \mathrm{kV}$.

\section{Post embedding colloidal-gold immunocytochemistry for osteoadherin}

The condylar processes from three alendronate-treated and two control rats from each group destined to immunocytochemical analizes were fixed under microwave irradiation as described previously. However, the fixative solution used for this group contained $0.1 \%$ glutaraldehyde and $4 \%$ formaldehyde buffered in $0.1 \mathrm{M}$ cacodylate, $\mathrm{pH}$ 7.4. The specimens were decalcified as described, dehydrated and embedded in LR White resin (London Resin Company, UK). Nickel grid-mounted $80 \mathrm{~nm}$ -
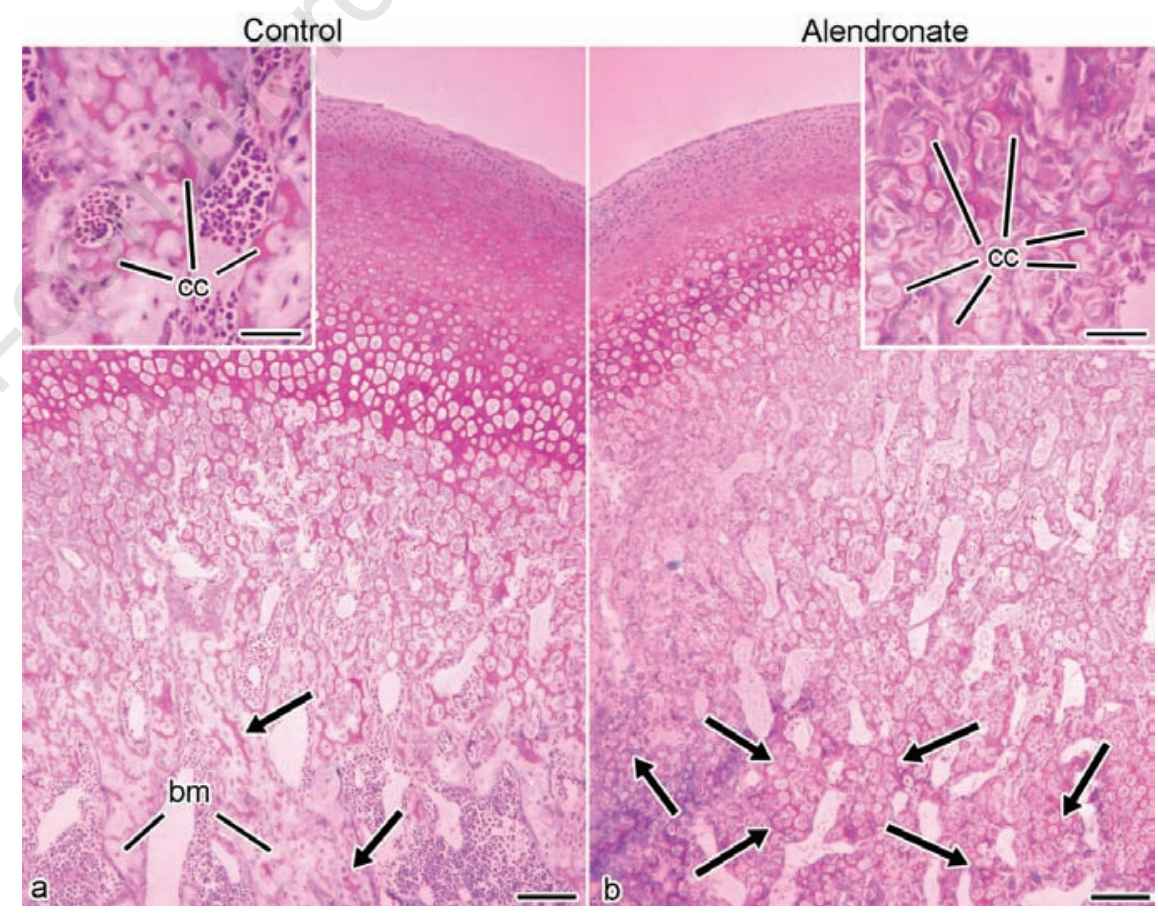

Figure 1. Light micrographs of hematoxylin and acid fuchsin-stained sections. At 30 days, condyles of control specimens in (a), present calcified cartilage (arrows) at the ossification area; the bone trabeculae $(\mathrm{bm})$ present remodeled appearance; scale bar: $80 \mu \mathrm{m}$. The inset illustrates the distal ossification portion at higher magnification, where few calcified cartilage areas surrounded by bone matrix are seen; scale bar: $20 \mu \mathrm{m}$. The alendronate-treated specimens in (b) present cartilage (arrows) at the ossification and in the interior of the trabeculae; scale bar: $80 \mu \mathrm{m}$. The inset shows numerous calcified cartilage septa with small amount of bone matrix secreted over them. CC, calcified cartilage. Scale bar: $20 \mu \mathrm{m}$. 
thick tissue sections were incubated 20 min on a drop of $0.01 \mathrm{M}$ phosphate-buffered saline (PBS) solution containing nonfat milk, and then transferred to a drop of rabbit anti-rat osteoadherin $^{8}$ for incubation for $24 \mathrm{~h}$ at room temperature, followed by incubation for $30 \mathrm{~min}$ at room temperature with protein A-gold complex. Negative controls for specificity of labeling consisted of incubating the sections with protein A-gold alone. The tissue sections were rinsed thoroughly with PBS followed by distilled water, and air-dried. The staining was made with uranyl acetate and lead citrate and sections were viewed in a Jeol 1010 transmission electron microscope operated at $80 \mathrm{kV}$.

\section{Results}

The regions analyzed were the calcified cartilage and ossification zones at the developing mandible of rats treated with sodium alendronate or saline solution since their day of birth until 4, 14 and 30 days.

\section{Light microscopy}

The hematoxylin and acid fuchsin-stained sections of control rats at all the time points revealed the calcified cartilage matrix at proximal areas of the condyle that is resorbed at the distal region in which only spongy bone is observed (Figure 1a). In the alendronate-treated specimens there is a prevalence of cartilage matrix inside the trabeculae of the mandibular ramus at distal areas (Figure 1b).

\section{Tartrate resistant acid phosphatase histochemistry}

At day 4, the control group presented numerous TRAP-positive clastic cells at the calcified cartilage and ossification zones (Figure 2a). They were multinucleated and attached to the calcified cartilage septa (Figure 2b). At the same time point, the alendronate-treated specimens presented as many TRAP-positive clastic cells at the same regions as the controls (Figure 2c); however, these cells did not appear to be attached to the mineralized surfaces. Otherwise, they were rounded and loose in the marrow spaces (Figure 2d). The specimens at day 14 presented numerous TRAP-positive cells at the same areas as day 4 did (Figure 2e), and most of them were resorbing the calcified cartilage (Figure 2f). Alendronate-treated condyles were also plenty of TRAP-positive cells (Figure 2g), but they still presented the same phenotype as alendronate-treated specimens at day 4 (Figure 2h). The endochondral ossification process persisted until day 30 , when the calcified cartilage and ossification zone still exhibited mult- inucleated and TRAP-positive cells (Figure 2i). The mandibular ramus of these animals presented thick remodeled bone trabeculae, and few osteoclasts were observed over them (Figure 2j). The specimens treated with alendronate also presented numerous TRAP-positive cells at calcified cartilage and ossification areas at day 30 (Figure 2k). However, unlike controls, their mandibular ramus presented thin trabeculae constituted of calcified cartilage covered by thin layer of bone matrix with non-remodeled appearance. It were observed some TRAP-positive clastic cells at medular spaces, still presenting the same latent phenotype observed in the treated specimens at 4 and 14 days.

\section{Transmission electron microscopy}

Ultrastructural analyzes showed, at the ossification zone of endochondral ossification, bone matrix deposited by osteoblasts over the calcified cartilage septa (Figure 3a). Multinucleated active clastic cells were adhered to the mineralized surfaces through their sealing zones, and presented exuberant ruffled border, clear zone and numerous vacuoles at the cytoplasm (Figure 3b). The alen- dronate-treated rats also presented calcified cartilage septa with bone matrix deposited by osteoblasts over them at the zone of ossification (Figure $3 \mathrm{c}, \mathrm{d}, \mathrm{e})$. The alendronate-treated clastic cells, when analyzed at the ultrastructural level, did not present the same phenotype of controls. Otherwise, they were not polarized, rounded-shaped and did not present adhesion structures and resorbing organelles such as clear zone and ruffled border (Figure $3 f$ ).

\section{Ultrastructural localization of osteoadherin}

Ultrathin sections of the mandibular ramus of 30 day old alendronate-treated specimens presented immunolabeling to OSAD at the bone matrix layer that covered the cartilage tags. The gold particles were localized adjacent to collagen fibrils (Figure 4a), in the interfibrillar spaces of the matrix (Figure 4b) and at appositional cement lines (Figure 4c). No gold particles were observed at the calcified cartilage matrix (Figure 4 a,b). Examining at the same region in control specimens, gold particles were found disperse in bone matrix (not shown).

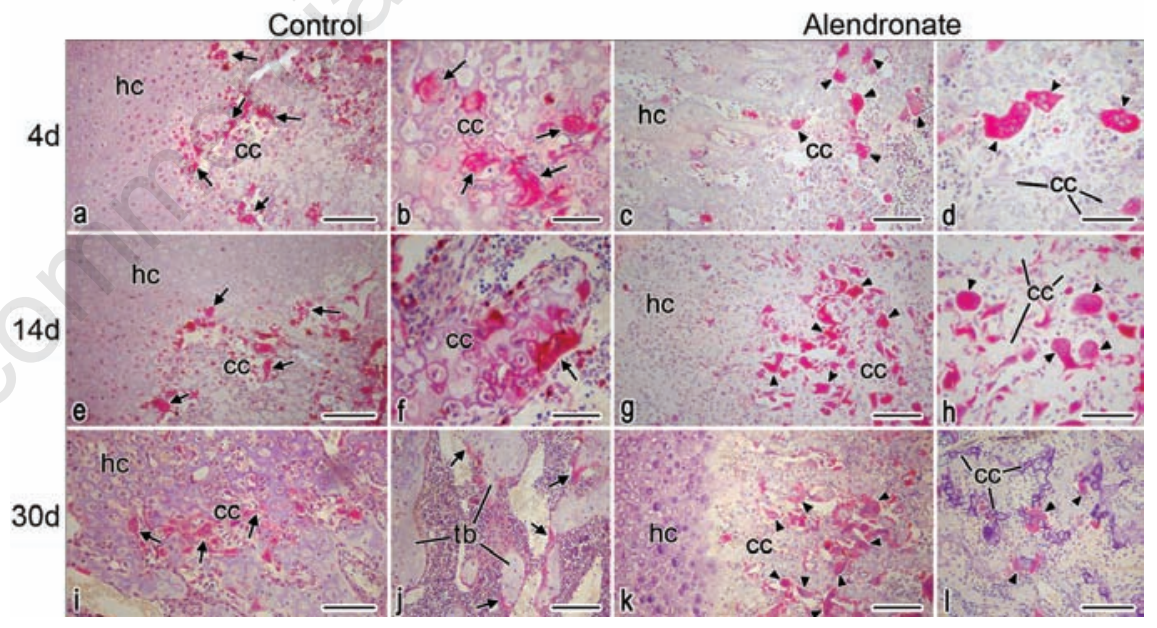

Figure 2. Light micrographs illustrating the endochondral ossification area of rat mandibles histochemically stained for tartrate resistant acid phosphatase (TRAP). At 4 days, control condyles $(a, b)$ presented hypertrophic cartilage (hc) and calcified cartilage (cc). Numerous TRAP-positive clastic cells (arrows) were resorbing the calcified cartilage septa at this moment. At the same time point, alendronate-treated specimens (c, d) presented TRAP-positive clastic cells (arrowheads) as well, but most cells appeared disperse in the spaces between calcified cartilage sept with no apparent resorbing activity. At 14 days the endochondral ossification persists in controls $(e, f)$, and numerous resorbing clastic cells are observed degrading the calcified cartilage matrix. In the alendronate group $(\mathrm{g}, \mathrm{h})$, the clastic cells did not show any signs of resorptive activity, remaining at the same phenotype observed at 4 days. At 30 days, the calcified cartilage is still being degraded at proximal areas in the condyle of controls $(i, j)$. At distal regions, the trabecular bone (tb) is already formed and some clastic cells are still remodelling the bone matrix. However, at the alendronate group $(k, 1)$, the clastic cells still presented the same phenotype observed at previous time points at proximal regions. At distal regions, the specimens presented trabeculae consisted of non-resorbed calcified cartilage where osteoblasts deposited bone matrix. There were non-resorbing clastic cells around the trabeculae. a, c, e, g, i, j, k, l, scale bars: $200 \mu \mathrm{m}$; b, d, f, h, scale bars: $20 \mu \mathrm{m}$. 


\section{Discussion}

Calcified cartilage fragments remained buried inside the formed bone trabeculae at the mandibular ramus of young rats due to the inactivation of resorptive activity of clastic cells by alendronate. The formed trabeculae were not substituted by lamellar bone during the endochondral ossification of the mandibular condyle when alendronate was administrated.

The alendronate-treated specimens showed numerous TRAP-positive multinucleated cells in the endochondral ossification taking place in the mandibular condyle. However, these cells exhibited latent phenotype because they were not adhered to the mineralized surfaces and therefore they did not present ultrastructural features of a resorbing cell, like sealing zone and ruffled border. ${ }^{23,32}$ Thus, the cartilage septa were covered by bone matrix and remained unremodeled as mandibular growth took place in the alendronate-treated rats. Contrarily, controls presented trabeculae of bone matrix at the mandibular ramus because both clastic cells were active: chondroclasts resorbed the calcified cartilage, and osteoclasts resorbed the primary bone trabeculae containing calcified cartilage septa. In addition, the presence of numerous latent osteoclasts suggests that alendronate treatment did not impede the recruitment of clastic cell precursors as well as their fusion, even in the high dose that was daily administered in our study, confirming previous studies in the alveolar process of jaw bones. ${ }^{23}$

During endochondral ossification, chondrocyte proliferation needs to be synchronized with clastic cell activity (resorption of calcified cartilage septa by chondroclasts and that of primary spongiosa by osteoclasts) for allowing mandible growth. Thus, alterations in chondrocyte proliferation or in chondrocyte hypertrophy after alendronate treatment were not expected findings. Moreover, the calcified cartilage septa serve as support for deposition of bone matrix in order to maintain the longitudinal growth of the region. The numerous inactivated clastic cells failed to resorb the cartilage septa. It resulted in the elongation of the cartilage layer in the mandibular ramus that may be related to the remaining calcified cartilage septa into the primary spongiosa rather than to the lack of hyperthophic cartilage removal by inactivated chondroclasts, as previously stated. ${ }^{28,29}$ Although bisphosphonates are believed to impair mineralization, ${ }^{11,17}$ our findings revealed no alterations in cartilage matrix mineralization in mandibular condyles from alendronate-treated rats. The areas of calcified cartilage matrix were devoid of the small proteoglycan OSAD, which was only present into the bone matrix. The ultrastructural immuno- labeling for OSAD showed a normal distribution of gold particles in the primary bone matrix around the cartilage septa, similar to controls, where immunolabeling was diffuse and disperse over the mature bone matrix, as previously reported. ${ }^{9}$

The current data on experiments that approached the condylar growth under bisphosphonate effects indicate that the clastic cells are inactivated during this process; however, none of them clarified their cellular structure with details. Our findings may contribute to the understanding of the cellular events that comprise the disturbances occasioned by alen-

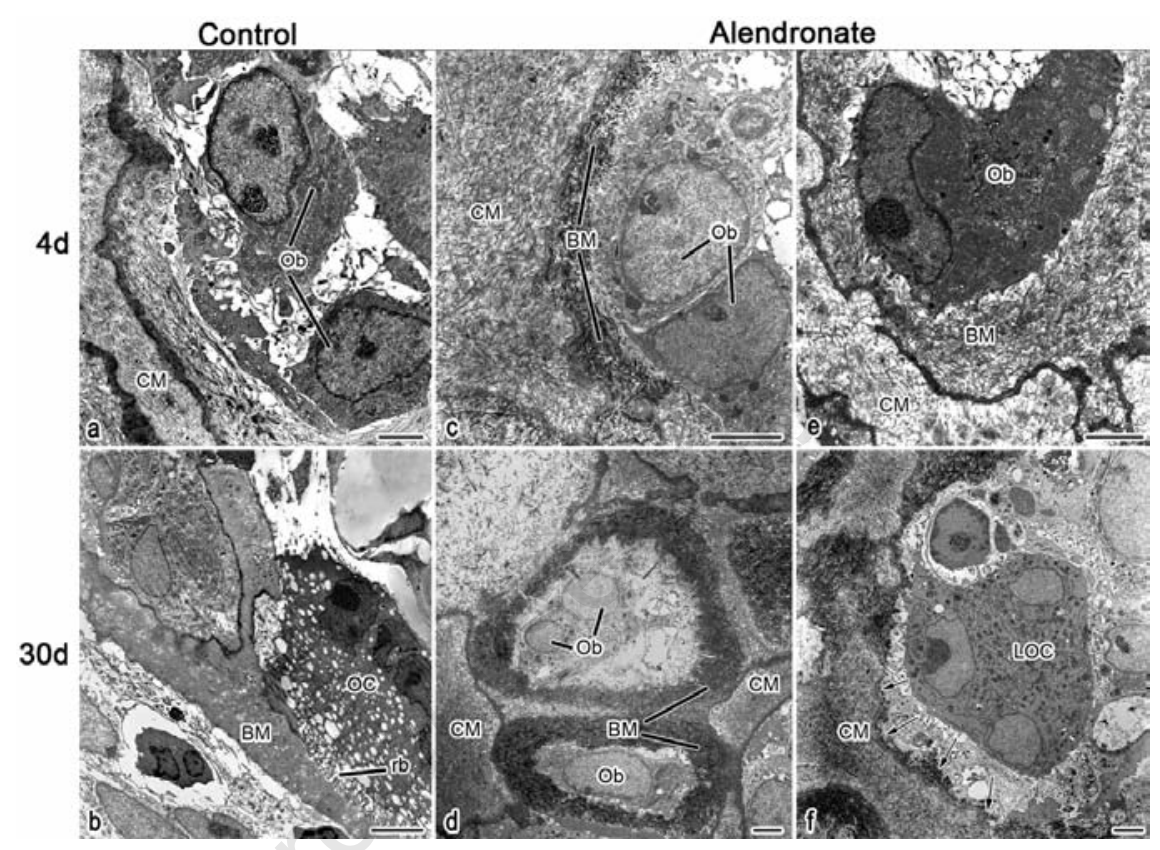

Figure 3. Transmission electron micrographs illustrating ultrastructural details of the ossification area of rat mandibles. At four days (a), osteoblasts $(\mathrm{Ob})$ were secreting bone matrix (BM) over the calcified cartilage tags (CM) in controls. This osteoblast activity was also observed at the alendronate group (c, d, e). At thirty days, controls presented active clastic cells resorbing the previously secreted bone matrix at trabecular bone of distal regions of the mandibular ramus $(b)$. The alendronate group presented cartilage matrix in the core of trabeculae at the same regions described in the control group (f). The clastic cells observed were not attached to the bone/cartilage surfaces at their most; however, sparse shallow resorption lacunae were present over these structures (arrows). LOC, latent osteoclast. Scale bars: $1.5 \mu \mathrm{m}$.
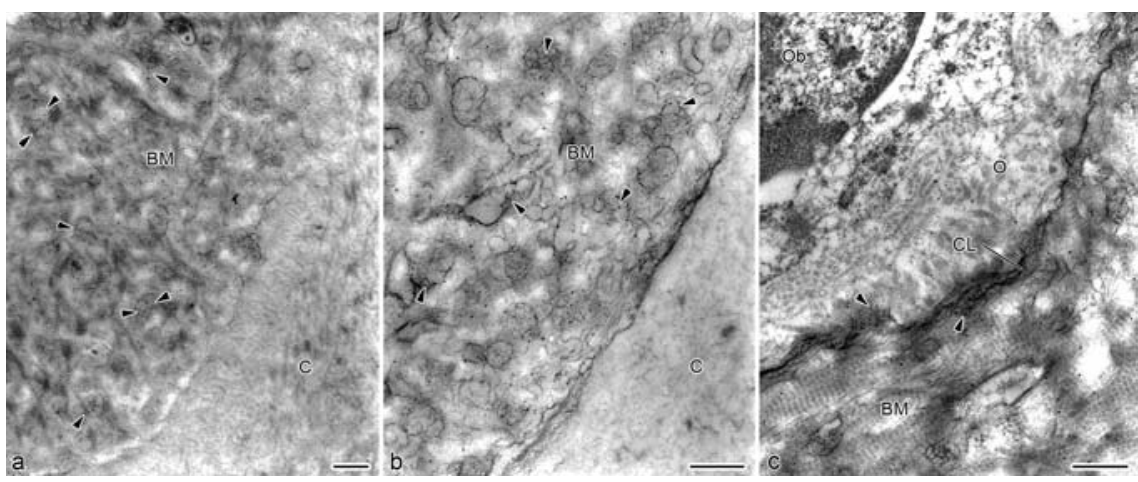

Figure 4. High resolution immunocytochemistry for osteoadherin (OSAD). Transmission electron micrographs illustrating colloidal-gold immunocytochemical detection of OSAD at bone trabeculae of mandibles of thirty day-old alendronate-treated rats. Colloidal gold particles (arrows) indicate the presence of OSAD in interfibrillar spaces of the primary bone matrix (BM) in (a) and (b.) The mineralized cartilage matrix (C) does not present labeling. In (c), the gold particles are detected in the cement line (CL) between the bone matrix and the osteoid (O). Ob, osteoblast. Scale bars: $400 \mathrm{~nm}$. 
dronate during endochondral ossification. The alendronate treatment of young rats significantly altered the endochondral ossification of the mandibular condyle. It did not impede the recruitment and fusion of precursors of the clastic cells, ${ }^{23}$ which were abundant at the ossification areas, but they remained latent and could not remodel the calcified cartilage/primary bone trabeculae into spongy bone at the mandibular ramus.

As bisphosphonate therapies are recommended for treatment of bone disorders during childhood such as osteogenesis imperfecta, juvenile Paget's disease and secondary osteoporosis related to anorexia nervosa, cerebral palsy and post-renal transplants, ${ }^{18-20}$ the present results highlight the risk of disturbing maxillofacial growth in young patients that take bisphosphonate therapy.

\section{References}

1. Ten Cate AR. Temporomandibular joint. In: Ten cate's oral histology - Development, structure and function. St. Louis, USA, Mosby, 2003, pp. 376-96.

2. de Moraes LOC, Lodi FR, Gomes TS, Marques SR, Oshima CTF, Lancellotti CLP, et al. Immunohistochemical expression of types I and III collagen antibodies in the temporomandibular joint disc of human foetuses. Eur J Histochem 2011;55:e24.

3. Marchi F, Luder HU, Leblond CP. Changes in cells secretory organelles and extracellular matrix during endochondral ossification in the mandibular condyle of the growing rat. Am J Anat 1991;190:41-73.

4. Arana-Chavez VE, Bradaschia-Correa V. Clastic cells: Mineralized tissue resorption in health and disease. Int $\mathrm{J}$ Biochem Cell Biol 2009;41:446-50.

5. Loreto C, Almeida LE, Migliore MR, Caltabiano M, Leonardi R. TRAIL, DR5 and caspase 3-dependent apoptosis in vessels of diseased human temporomandibular joint disc. An immunohistochemical study. Eur J Histochem 2010;54:e40.

6. Kiga N, Tojyo I, Matsumoto T, Hiraishi Y, Shinohara Y, Fujita S. Expression of lumican related to CD34 and VEGF in the articular disc of the human temporomandibular joint. Eur J Histochem 2010;54:e34.

7. Kiga N, Tojyo I, Matsumoto T, Hiraishi Y, Shinohara Y, Makino S, et al. Expression of lumican and fibromodulin following interleukin-1 beta stimulation of disc cells of the human temporomandibular joint. Eur J Histochem 2011;55:e11.
8. Couble M-L, Bleicher F, Farges J-C, Peyrol $\mathrm{S}$, Lucchini $\mathrm{M}$, Magloire $\mathrm{H}$, et al. Immunodetection of osteoadherin in murine tooth extracellular matrices. Histochem Cell Biol 2004;121:47-53.

9. Ramstad VE, Franze'n A, Heinegard D, Wendel M, Reinholt FP. Ultrastructural distribution of osteoadherin in rat bone shows a pattern similar to that of bone sialoprotein. Calcif Tissue Int 2003;72:5764.

10. Shen Z, Gantcheva S, Sommarin Y, Heinegard D. Tissue distribution of a novel cell binding protein, osteoadherin, in the rat. Matrix Biol 1999;18:533-42.

11. Russell RG, Watts NB, Ebetino FH, Rogers MJ. Mechanisms of action of bisphosphonates: similarities and differences and their potential influence on clinical efficacy. Osteoporos Int 2008;19:733-59.

12. Rogers MJ, Gordon S, Benford HL, Coxon FP, Luckman SP, Monkkonen J, et al. Cellular and molecular mechanisms of action of bisphosphonates. Cancer 2000;88:2961-78.

13. Vasikaran SD. Bisphosphonates: an overview with special reference to alendronate. Ann Clin Biochem 2001;38:60823.

14. Halasy-Nagy JM, Rodan GA, Reszka AA. Inhibition of bone resorption by alendronate and risedronate does not require osteoclast apoptosis. Bone 2001;29:553-9.

15. Helm NB, Padala S, Beck FM, D'Atri AM, Huja SS. Short-term zoledronic acid reduces trabecular bone remodeling in dogs. Eur J Oral Sci 2010;118:460-5.

16. Wu X, Pang L, Lei W, Lu W, Li J, Li Z, et al. Inhibition of Sca-1-positive skeletal stem cell recruitment by alendronate blunts the anabolic effects of parathyroid hormone on bone remodeling. Cell Stem Cell 2010;7: $571-80$.

17. Bodde EW, Kowalski RS, Spauwen PH, Jansen JA. No increased bone formation around alendronate or omeprazole loaded bone cements in a femoral defect. Tissue Eng Part A 2008;14:29-39.

18. Maasalu K, Haviko T, Martson A. Treatment of children with osteogenesis imperfecta in Estonia. Acta Paediatr 2003;92:452-5.

19. Kamoun-Goldrat A, Ginisty D, Le Merrer M. Effects of bisphosphonates on tooth eruption in children with osteogenesis imperfecta. Eur J Oral Sci 2008;116:195-8.

20. Bachrach LK, Ward LM. Clinical review: bisphosphonate use in childhood osteoporosis. J Clin Endocrinol Metab 2009; 94:400-9.

21. Massa LF, Bradaschia-Correa V, Arana-
Chavez VE. Immunocytochemical study of amelogenin deposition during the early odontogenesis of molars in alendronatetreated newborn rats. J Histochem Cytochem 2006;54:713-725.

22. Grier RL, Wise GE Inhibition of tooth eruption in the rat by a bisphosphonate. J Dent Res 1998;77:8-15.

23. Bradaschia-Correa V, Massa LF, AranaChavez VE. Effects of alendronate on tooth eruption and molar root formation in young growing rats. Cell Tissue Res 2007;330:475-85.

24. Evans KD, Lau ST, Oberbauer AM, Martin RB. Alendronate affects long bone length and growth plate morphology in the oim mouse model for Osteogenesis Imperfecta. Bone 2003;32:268-74.

25. Larsson A. The effects of ethylene-1,1-disphosphonate on the developing mandibular condyle - a light microscopic study. Acta Odontol Scand 1977;35:217-23.

26. Larsson A, Larsson S-E. The effects of thylene-1,1-disphosphonate on cellular transformation and organic matrix of the epiphyseal growth plate of the rat - a light microscopic and ultrastructural study. Acta Pathol Microbiol Scand A 1978;86:211-23.

27. Tabuchi M, Miyazawa K, Kimura M, Maeda H, Kawai T, Kameyama Y, et al. Enhancement of crude bone morphogenetic protein-induced new bone formation and normalization of endochondral ossification by bisphosphonate treatment in osteoprotegerin-deficient mice. Calcif Tissue Int 2005;77:239-49.

28. Kimura M, Miyazawa K, Tabuchi M, Maeda H, Kameyama Y, Goto S. Bisphosphonate treatment increases the size of the mandibular condyle and normalizes growth of the mandibular ramus in osteoprotegerin-deficient mice. Calcif Tissue Int 2008;82:137-47.

29. Kim MS, Jung SY, Kang JH, Kim HJ, Ko HM, Jung JY, et al. Effects of bisphosphonate on the endochondral bone formation of the mandibular condyle. Anat Histol Embryol 2009;38:321-6.

30. Massa LF, Arana-Chavez VE. Ultrastructural preservation of rat embryonic dental tissues after rapid fixation and dehydratation under microwave irradiation. Eur J Oral Sci 2000;108:74-7.

31. Casa MA, Faltin RM, Faltin K, AranaChavez VE. Root resorption on torqued human premolars shown by tartrateresistant acid phosphatase histochemistry and transmission electron microscopy. Angle Orthod 2006;76:1015-21.

32. Lerner UH. Osteoclast formation and resorption. Matrix Biol 2000;19:107-20. 